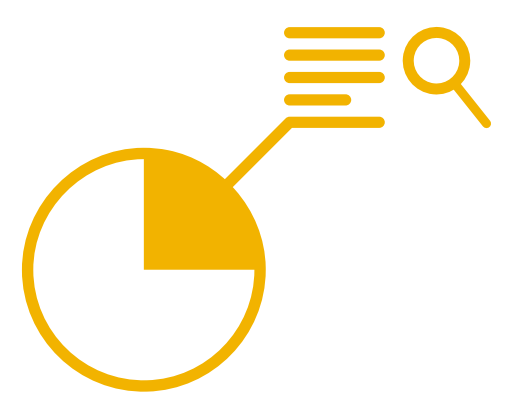

\title{
ANÁLISE DO PERFIL EPIDEMIOLÓGICO DE PACIENTES SUBMETIDOS A TRANSPLANTE DE CÓRNEA: REVISÃO INTEGRATIVA
}

\author{
ANALYSIS OF EPIDEMIOLOGICAL PROFILE OF CORNEAL TRANSPLANT PATIENTS: \\ AN INTEGRATIVE REVIEW.
}

\begin{abstract}
Valeria da Rocha Soares
Mestranda em Gestão e Inovação em Saúde pela Universidade Federal do Rio Grande do Norte (UFRN). Especialista em Enfermagem em Centro Cirúrgico e Central de Material pela Faculdade Unyleya. Esp. em Enfermagem do Trabalho pelo Centro Universitário São Camilo. Enfermeira do Hospital Universitário Cassiano Antônio Moraes (HUCAM-UFES). E-mail: valeria_rochasoares@hotmail.com.
\end{abstract}

\section{Ricardo Fernando Arrais}

Doutorado em Ciências (Endocrinologia Clínica) pela Universidade Federal de São Paulo. Residência Médica em Pediatria no Hospital São Paulo. Pesquisador do Laboratório de Inovação Tecnológica em Saúde (LAIS) da UFRN. Docente Associado do Departamento de Pediatria da Universidade Federal do Rio Grande do Norte (UFRN). E-mail: rifarrais@gmail.com.

\section{Gilmara Barbosa de Melo Silva}

Mestranda em Gestão e Inovação em Saúde pela Universidade Federal do Rio Grande do Norte (UFRN).

Especialista em Gestão do Trabalho e Educação em Saúde pela Universidade Federal do Rio Grande do Norte (UFRN). Enfermeira do Complexo Hospital de Clínicas do Paraná (CHC-UFPR). E-mail: gil-mara-dasilva@hotmail.com.

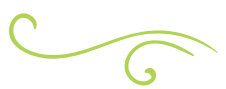

\section{RESUMO}

Estudos têm revelado que a segunda causa de cegueira reversível no mundo tem sido as doenças da córnea que acometem indivíduos jovens com vida ativa em plena atividade, gerando, consequentemente, importante perda econômica e social. Uma alternativa para a reversão das doenças corneanas é o transplante que cresce a cada ano no Brasil. Compreender o perfil epidemiológico de pacientes submetidos a transplante penetrante de córnea no Brasil. Revisão integrativa de literatura. As bases de dados utilizadas foram: (SCIELO), Web of Science via Portal de periódicos da CAPES, (MEDLINE), (Cochrane) via Biblioteca Virtual em Saúde e (PUBMED). Processo realizado entre os meses de setembro e outubro de 2018. Os critérios de inclusão foram: produções publicadas em inglês, espanhol e português, artigos disponíveis na íntegra que retratassem o perfil epidemiológico de pacientes submetidos a transplante de córnea, com foco no receptor. De acordo com o estudo realizado, o ceratocone é a principal causa para realização de cirurgia de transplante de córnea, porém, o mesmo 
estudo apontou variações na prevalência em diferentes regiões e serviços de referência no Brasil. Os aspectos epidemiológicos variam entre as regiões, porém, é possível identificar grupos de mais vulnerabilidade e principais problemas que atingem a córnea com necessidade de intervenção cirúrgica, nessa temática estudada, a cirurgia de transplante.

Palavras-chave:Transplante de córnea. Perfil epidemiológico. Epidemiologia.

\section{ABSTRACT}

Studies have revealed that the second cause of reversible blindness in the world has been corneal diseases that affect young individuals with active lives in full activity, consequently generating significant economic and social loss. An alternative for reversing corneal diseases is the transplant that grows each year in Brazil. To understand the epidemiological profile of patients undergoing penetrating corneal transplantation in Brazil. Integrative literature review. The databases used were: (SCIELO), Web of Science via CAPES Journal Portal, (MEDLINE), (Cochrane) via Virtual Health Library and (PUBMED). Held between September and October 2018. The inclusion criteria were: productions published in English, Spanish and Portuguese, articles available in full that portray the epidemiological profile of patients undergoing corneal transplantation, focusing on the receiver. According to the study, keratoconus is the main cause for corneal transplant surgery, however, the same studies showed variations in prevalence in different regions and referral services in Brazil. The epidemiological aspects vary between regions, but it is possible to identify groups of greater vulnerability and major problems that affect the cornea in need of surgical intervention, in this studied theme, transplantation.

Key-words: Corneal transplantation. Health profile. Epidemiology.

\section{INTRODUÇÃO}

Estudos têm revelado que a segunda causa de cegueira reversível no mundo tem sido as doenças da córnea que acometem indivíduos jovens com vida ativa em plena atividade, gerando, consequentemente, importante perda econômica e social. Uma alternativa para reversão das doenças corneanas é o transplante, que cresce a cada ano no Brasil (ALMEIDA; SOUZA, 2014).

O Brasil possui o maior sistema público de transplantes do mundo. Em 2018, foram realizados 14.809 transplantes de córnea, de acordo com a Associação Brasileira de Transplantes de Órgãos. De janeiro a março de 2019, foram realizados 3.400 transplantes em todo o país (BRASIL, 2019). A técnica cirúrgica de transplante de córnea vem sendo aprimorada com o passar dos tempos em decorrência dos avanços tecnológicos associados às melhores formas de conservação e preparação da córnea obtida pelo processo de doação (GAIN et al., 2016).

Partindo dessas informações expostas e levando em consideração a importância de compreender as tendências da substituição da córnea, a presente pesquisa busca responder à seguinte pergunta: qual o perfil epidemiológico dos pacientes submetidos a transplante de córnea? Este estudo se justifica pela necessidade de entender o perfil epidemiológico dos pacientes submetidos a transplantes de córnea, identificando suas características para fornecer informações pertinentes aos métodos de prevenção e controle. Para propiciar uma assistência de qualidade a essa clientela, é importante o raciocínio crítico e reflexivo com base no conhecimento científico. Tendo por base o exposto, esta revisão tem o objetivo de identificar as evidências disponíveis na literatura sobre o perfil epidemiológico dos pacientes submetidos a transplante de córnea, com foco no receptor. 


\section{MÉTODO}

Trata-se de uma revisão integrativa da literatura seguindo algumas etapas, entre elas: (1) elaboração da questão norteadora; (2) busca na literatura; (3) coleta de dados e categorização dos estudos; (4) análise crítica dos estudos incluídos; (5) interpretação e discussão dos resultados e (6) apresentação da revisão/síntese do conhecimento. Organizou-se a partir da seguinte questão norteadora: quais as evidências publicadas quanto ao perfil epidemiológico de pacientes submetidos a transplante de córnea, com foco no receptor?

As bases de dados utilizadas foram: Scientific Eletronic Library Online (SCIELO), Web of Science via Portal de periódico CAPES, Medical Literature Analysis and Retrieval System Online (MEDLINE), The Cochrane Lubrary (Cochrane) via Biblioteca Virtual em Saúde e U.S. National Library of Medicine (PUBMED) dos últimos 05 anos. A busca foi realizada entre os meses de agosto e setembro de 2019.

Para a busca nacional, foram utilizados os seguintes descritores: transplante de córnea, perfil de saúde e epidemiologia. Para a busca das publicações internacionais, os descritores utilizados foram: corneal transplantation, trasplante de córnea, health profile, perfil de salud, epidemiology e epidemiología.

Os critérios de inclusão foram: produções publicadas nos idiomas: inglês, espanhol e português, artigos disponíveis na íntegra que retratassem o perfil epidemiológico dos pacientes submetidos a transplante de córnea, com foco no receptor. Para a seleção das publicações, foram analisados inicialmente o título e o resumo a fim de confirmar se contemplavam os critérios de inclusão. Posteriormente, os estudos selecionados foram lidos na íntegra com a finalidade de verificar a pertinência dos trabalhos à resposta da questão de pesquisa.

Das bases de dados incluídas, obteve-se um total de 12 artigos. Desses, 02 se repetiram na base de dados, 04 não se enquadravam nos critérios de inclusão, sendo inicialmente selecionados 07 artigos. Desse total, 03 foram excluídos por serem publicações antigas: 2004, 2005 e 2006, 01 por trazer o foco no doador e não no receptor. Restando 03 artigos, conforme Figura 1. Os resultados foram apresentados de forma descritiva, em quadro contendo dados referentes a autoria, ano, objetivo do estudo, intervenções, resultados e conclusões.

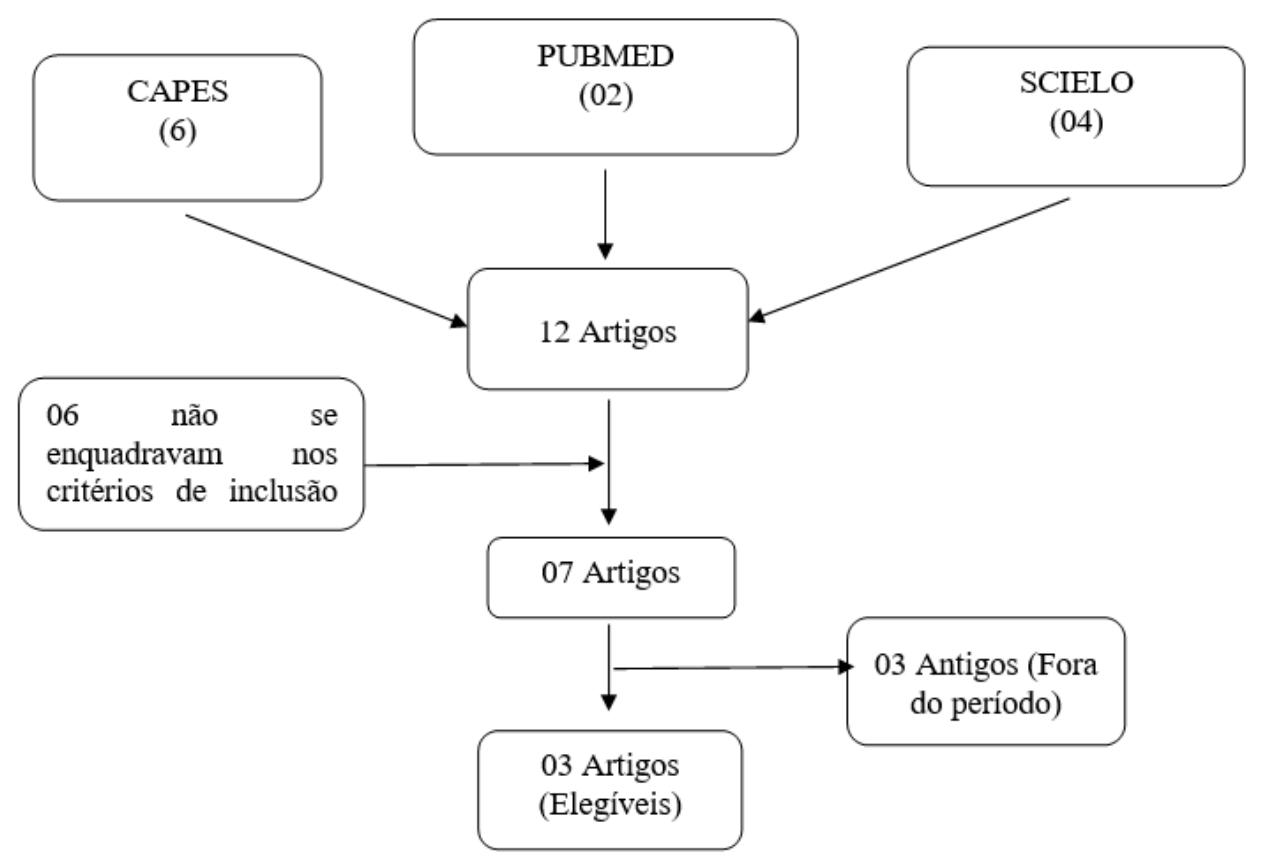

Figura 1 - Fluxograma de seleção dos artigos por base de dados, Vitória-ES, Brasil, 2020 Fonte: elaborado pelos autores. 
RESULTADOS

Os três artigos selecionados foram elaborados em língua portuguesa. Quanto ao local de estudo, dois foram realizados em São Paulo e um no Rio Grande do Norte. Com relação ao ano de publicação, a mais antiga data do ano de 2017 e 2018 respectivamente. $\mathrm{O}$ desenho de coleta de dados dos estudos selecionados foram os seguintes: um estudo retrospectivo e analítico utilizando dados do Sistema Nacional de Transplantes, estudo epidemiológico de abordagem quantitativa e análise crítica analítica. Logo abaixo, no quadro 1, estão esboçados alguns aspectos do processo de transplante de córnea de acordo com os artigos selecionados.

Quadro 1 - Síntese dos artigos selecionados sobre transplante de córnea.

\begin{tabular}{|c|c|c|c|c|}
\hline $\begin{array}{c}\text { AUTORES, } \\
\text { LOCAL E ANO }\end{array}$ & OBJETIVO & $\begin{array}{l}\text { DESENHO DO } \\
\text { ESTUDO }\end{array}$ & $\begin{array}{c}\text { AMOSTRA E } \\
\text { INTERVENÇÕES }\end{array}$ & $\begin{array}{l}\text { RESULTADOS E } \\
\text { CONCLUSÕES }\end{array}$ \\
\hline $\begin{array}{l}\text { Almeida, H. G; Hida, R. } \\
\text { Y; Kara Junior, N. São } \\
\text { Paulo, } 2018 .\end{array}$ & $\begin{array}{l}\text { Analisar as tendências } \\
\text { do transplante de } \\
\text { córnea no Brasil de } \\
2001 \text { a } 2016 \text {. }\end{array}$ & $\begin{array}{l}\text { Estudo retrospectivo e } \\
\text { analítico. }\end{array}$ & $\begin{array}{l}\text { Baseado em dados do } \\
\text { Sistema Nacional de } \\
\text { Transplantes de } 184.575 \\
\text { transplantes de córnea } \\
\text { realizados no período } \\
\text { de janeiro de } 2001 \text { a } \\
\text { dezembro de } 2016 \text {. }\end{array}$ & $\begin{array}{l}\text { No Brasil, houve um } \\
\text { aumento: de } 2,4 \text { vezes no } \\
\text { número de transplantes } \\
\text { de córnea; de } 50,7 \% \text { na } \\
\text { eficácia de atender a } \\
\text { demanda populacional de } \\
\text { transplantes de córnea; } \\
\text { de } 11 \text { vezes no número de } \\
\text { centros de transplantes } \\
\text { de córnea (de } 32 \text { para } \\
\text { 356); e de 2,5 vezes no } \\
\text { número de equipes } \\
\text { transplantadoras de } \\
\text { córnea (de } 276 \text { para 688). } \\
\text { A lista de espera para o } \\
\text { transplante de córnea } \\
\text { diminuiu em } 45,4 \% \text {. }\end{array}$ \\
\hline $\begin{array}{l}\text { Cruz, G. K. P et al. } \\
\text { Rio Grande do Norte, } 2017 .\end{array}$ & $\begin{array}{l}\text { Caracterizar } \\
\text { clinicamente } \\
\text { os pacientes } \\
\text { transplantados e } \\
\text { sua distribuição } \\
\text { com descrição das } \\
\text { condições indicadoras } \\
\text { e pós-operatórias } \\
\text { dos transplantes de } \\
\text { córneas, bem como } \\
\text { estimar o tempo médio } \\
\text { em fila de espera. }\end{array}$ & $\begin{array}{l}\text { Estudo epidemiológico, } \\
\text { transversal, descritivo e } \\
\text { analítico, realizado com } \\
\text { todos os transplantes de } \\
\text { córnea realizados em um } \\
\text { serviço de referência. }\end{array}$ & $\begin{array}{l}\text { A técnica de amostragem } \\
\text { utilizada foi do tipo não } \\
\text { probabilística, uma vez } \\
\text { que envolveu todos os } \\
\text { pacientes transplantados } \\
\text { com córneas pelo serviço } \\
\text { estudado entre o período } \\
\text { de janeiro de } 2010 \text { a } \\
\text { dezembro de } 2014 \text {. }\end{array}$ & $\begin{array}{l}\text { A principal condição } \\
\text { indicadora para o } \\
\text { transplante de córnea } \\
\text { foi o ceratocone. } 0 \\
\text { tempo médio em fila de } \\
\text { espera para realização } \\
\text { do transplante foi de } \\
\text { aproximadamente } 5 \\
\text { meses e três semanas } \\
\text { para os transplantes } \\
\text { eletivos e } 9 \text { dias para os } \\
\text { casos de urgência. Existiu } \\
\text { associação entre o tipo de } \\
\text { distúrbio da córnea com } \\
\text { sexo, faixa etária, cirurgia } \\
\text { prévia, classificação do } \\
\text { olho, glaucoma e falência } \\
\text { do enxerto anterior. } O \\
\text { ceratocone foi a principal } \\
\text { condição indicadora } \\
\text { para o transplante de } \\
\text { córnea. Fatores como } \\
\text { idade, falência de enxerto } \\
\text { corneano anterior } \\
\text { (retransplante), glaucoma, } \\
\text { casos de cirurgias prévias } \\
\text { ao transplante de córnea, } \\
\text { com destaque para a } \\
\text { cirurgia de catarata, } \\
\text { podem estar relacionados } \\
\text { com o aparecimento de } \\
\text { distúrbios da córnea do } \\
\text { tipo endotelial. }\end{array}$ \\
\hline
\end{tabular}


Almeida, H. G; Kara

Junior, N. São Paulo, 2018.
Avaliar a precisão

dos dados e a

confiabilidade das

informações divulgadas

pelo SNT, ABTO

e ANVISA sobre a

situação do transplante

de córnea no Brasil.
Estudo de revisão narrativa e analítica, que tem como enfoque a análise crítica dos dados divulgados sobre transplantes de córnea e ABTO no Brasil no período de janeiro de 2002 a dezembro de 2016
A pesquisa de dados desenvolveu-se no período de outubro a dezembro de 2017 , baseada na legislação brasileira sobre transplante de órgãos e tecidos, em artigos científicos publicados sobre o tema e indexados nas bases eletrônicas de dados.
No Brasil, a ABTO

divulga anualmente, desde 1997, nas línguas portuguesa e inglesa, - Registro Brasileiro de Transplantes (RBT), com dados nacionais regionais de todos os tipos de transplantes realizados no país, incluindo os transplantes de córnea.

Os dados divulgados anualmente pelo SNT, ABTO e ANVISA são fundamentais para monitoramento e avaliação da situação do transplante de córnea no Brasil. Porém, ainda são dados divergentes, incompletos e insuficientes para traçar uma correta análise sobre as dificuldades e os progressos relacionados aos transplantes de córnea realizados e os bancos de tecidos oculares em funcionamento no Brasil.

Fonte: elaborado pelos autores.

Dos artigos analisados, os fatores relacionados a idade e sexo foram evidenciados a partir da apresentação de casos clínicos com agravos e problemas de saúde mais graves que desencadearam a indicação de transplante de córnea. Quanto à principal causa para esse tipo de intervenção cirúrgica, estudo no Brasil apontou o ceratocone entre as patologias identificadas. $\bigcirc$ mesmo estudo alertou ainda sobre uma diminuição considerável na lista de espera para esse tipo de transplante, apesar dos números baixos de doação.

Os dados levantados no presente estudo indicam que ceratocone e a ceratopatia bolhosa constituem as principais causas de transplante de córnea. Apontam também que os procedimentos mais realizados são de dois tipos: a ceratoplastia penetrante ou ceratoplastia lamelar anterior profunda (CRUZ et al., 2017).

Além disso, estudos têm demonstrado as técnicas eficazes para utilizar em caso de transplante de córnea, bem como a contribuição na redução na lista de espera no Brasil. Segundo estudo, no Brasil, ocorreram aumentos: de 2,4 vezes no número de transplantes de córnea, de 50,7\% na eficácia de atender a demanda populacional de transplantes de córnea de 11 vezes no número de centros de transplantes de córnea (de 32 para 356); e de 2,5 vezes no número de equipes transplantadoras de córnea (de 276 para 688) (ALMEIDA; HIDA; KARA JUNIOR, 2018).

\section{DISCUSSÃO}

Tem sido demonstrado em estudo realizado no Brasil que o transplante de córnea é o tipo de cirurgia de maior sucesso entre os transplantes teciduais em humanos. 0 Brasil possui um sistema de transplante robusto e tecnicamente atualizado, reconhecido internacionalmente e é hoje o maior sistema público de transplantes no mundo, com mais de 20.000 intervenções 
cirúrgicas anuais entre órgãos, córneas e medula. Os transplantes de córnea correspondem a mais de $50 \%$ desse quantitativo. Cerca de $90 \%$ dos transplantes de órgãos do país são feitos com recursos públicos (ALMEIDA; SOUZA, 2014).

É importante descrever que o transplante de órgãos é um procedimento cirúrgico, realizado por meio do processo de reposição de um órgão ou tecido do corpo de uma pessoa doente denominado receptor, por um órgão ou tecido de outra pessoa saudável, definido como doador. Esse doador (pessoa) pode ser vivo ou morto (BRASIL, 2017).

Portanto, o transplante de córnea é um procedimento cirúrgico indicado com o objetivo de restaurar a função visual nos casos em que ocorrem doenças que acometem o tecido corneano, causando danos à visão que podem se tornar graves e até mesmo levar à perda da função. Esse tipo de transplante é considerado o mais frequente no Brasil e nos demais países do mundo (CRUZ et al., 2017).

A lei brasileira de transplante é de 1997, apesar da existência de leis anteriores a essa data, essas não apresentavam as características necessárias para garantir direitos, obrigações e deveres dos envolvidos no processo. No Brasil, esse controle é realizado em bancos de tecidos oculares seguindo as normas da Agência Nacional de Vigilância Sanitária (ANVISA) e do Sistema Nacional de Transplantes (ABTO) e de acordo com as recomendações Internacionais (BRASIL, 2009).

Para realizar uma cirurgia de transplante, o paciente deve estar inscrito na fila de espera por uma equipe especializada e autorizada pelo Ministério da Saúde. À equipe de transplante caberá a responsabilidade de realizar a inscrição no sistema informatizado de gerenciamento (SIG), o qual é coordenado pelo sistema nacional de transplantes (SNT). Essa inscrição gera automaticamente um número denominado Registro Geral de Cadastro Técnico (RGCT). Esse número identifica o paciente no cadastro único na fila de espera, possibilitando a obtenção de informações sobre a situação dos pacientes à espera de transplantes (BONFADINI et al., 2014).

Percebe-se, conforme estudos, a possibilidade de traçar o perfil de pacientes transplantados em diferentes espaços demográficos, permitindo comparar e analisar as variáveis que determinam os mais diversos desfechos envolvendo o transplante de córnea. Ao analisar o perfil epidemiológico de pacientes com indicação para realizar um transplante de córnea, foram identificadas variações regionais. Em estudos realizados no Estado do Pará/Brasil, a úlcera corneana foi considerada a principal indicação para o transplante de córnea, seguida por leucoma e ceratopatia bolhosa (SMINKEY, 2018; BENTLEY; PHILLIPS, 2017).

Esse achado difere do estudo realizado por Zeschau et al. (2013), que identificou o ceratocone como principal causa para realização de cirurgia de transplante de córnea. O mesmo estudo, concordando com dados observados na presente revisão, também apontou variações na prevalência em diferentes regiões e serviços de referência no Brasil.

Um aspecto interessante observado por Zeschau et al. (2013) faz menção à influência das condições sociodemográficas dos pacientes com indicação ao transplante (úlcera de córnea), considerando que a maioria deles era da zona rural. O estudo conclui, portanto, que essa variação foi devido à maior chance de trauma corneano grave em pessoas que vivem nas zonas rurais, onde há pouca utilização de equipamentos de proteção individual nos trabalhos em campo.

De certo, como se pode aferir nos dados coletados na literatura, as doenças da córnea se destacam bastante nas diferentes regiões do Brasil, tendo um importante peso por resultarem em muitos casos deficiências visuais e por atingirem mais a população adulta, podendo causar um grande impacto econômico e social. 
De acordo com outras pesquisas, realizadas para analisar o perfil epidemiológico de pacientes com indicação de transplante de córnea no estado de Pernambuco, entre 871 pacientes avaliados, 54\% eram mulheres e a maioria estava na faixa etária entre 61 a 80 anos. Quanto à indicação, neste estudo, a maioria teve como diagnóstico o leucoma, seguido por ceratocone (ALMEIDA; SOUZA, 2014).

Em contrapartida, conforme dados analisados em outros estudos, existem outras indicações que apontam a substituição da córnea. Foi o que demostrou estudo realizado no estado de Sergipe, o qual apontou a distrofias corneanas como principal motivo para o transplante, sendo a ceratopatia bolhosa a maior entre elas. Quando se avaliou a média da faixa etária, concluiu-se que a média de idade foi entre 50 a 62 anos, sendo mais frequente no sexo feminino e nos residentes do interior do estado de Sergipe (CERQUEIRA; VITOR; NOGUEIRA, 2016).

A ceratopatia bolhosa é causada pelo edema da córnea, devido à falha do endotélio da córnea em manter o estado desidratado normal da córnea. É quase sempre devido à distrofia endotelial da córnea de Fuchs ou trauma ao endotélio da córnea. A distrofia de Fuchs é um distúrbio genético que causa perda progressiva e bilateral das células endoteliais da córnea, que, às vezes, leva à ceratopatia bolhosa sintomática dos 50 a 60 anos de idade. A distrofia de Fuchs pode ser autossômica dominante com penetrância incompleta. Outra causa comum de ceratopatia bolhosa é o trauma no endotélio da córnea, que pode ocorrer durante uma cirurgia intraocular (por exemplo, remoção de catarata) ou após o implante de uma lente intraocular inadequada ou mal colocada (SHARMA et al., 2015).

Em seus estudos, Cruz et al. (2017) afirmam que doenças oculares ocorrem com mais incidência nos países em desenvolvimento, sendo essas doenças, em sua maioria, evitáveis ou tratáveis. Quando analisou estudos realizados no Brasil, informações atuais chanceladas pela Organização Mundial da Saúde (OMS) indicam que o número de indivíduos com deficiência visual é estimado em cerca de 285 milhões, desses, 39 milhões de pessoas possuem diagnóstico de cegueira. Noventa por cento dessas pessoas com deficiência visual vivem em ambientes de baixa renda e $80 \%$ podem ser curadas ou seu comprometimento pode ser evitado.

\section{CONCLUSÃO}

Observa-se que o ceratocone e a ceratopatia são as principais doenças identificadas nos pacientes que tiveram indicação de transplante de córnea de acordo com os estudos disponibilizados. A úlcera de córnea teve incremento em regiões menos desenvolvidas, a exemplo de zonas rurais, ou interiores de acesso difícil. É possível concluir que esse agravo está relacionando com questões sociais, falta de ações de prevenção e controle.

O sexo feminino teve mais indicação de transplante, porém, com pouca diferença em relação ao sexo masculino. Em relação à faixa etária, houve variação em relação ao estudo avaliado, no entanto, foi possível identificar que os pacientes com idade entre 40 a 60 anos têm mais prevalência na indicação de transplantes.

Os aspectos epidemiológicos variam entre as regiões, entretanto, é possível identificar grupos com mais vulnerabilidade e os principais problemas que atingem a córnea com necessidade de intervenção cirúrgica. Existem poucos estudos atualizados no Brasil sobre a temática abordada neste trabalho. Muitos dos existentes são divergentes, incompletos e insuficientes para traçar uma correta análise.

Com a presente revisão, observou-se um perfil epidemiológico dos pacientes submetidos ao transplante de 
córnea, proporcionando, dessa forma, informações que podem ser usadas para nortear as ações de prevenção, promoção e controle, além de delinear melhores práticas e condutas na realização do procedimento cirúrgico, quando recomendado.

Sugere-se estudo que seja realizado por meio de elaboração e acompanhamento de indicadores de saúde, com estudos mais aprofundados sobre a temática. É sempre primordial conhecer a origem do problema de saúde, determinar com mais precisão os locais de mais risco e identificar as causas principais, para ter consciência e conhecimento sobre promoção e prevenção nos diversos níveis de atenção à saúde. 


\section{REFERÊNCIAS}

ALMEIDA, H.G.; SOUZA, A.C.D. Perfil epidemiológico de pacientes na fila de transplante de córnea no estado de Pernambuco - Brasil. Rev. bras.oftalmol., Rio de Janeiro, v. 73, n. 1, p. 28-32, 2014. Disponível em: http://www.scielo.br/scielo.php?script=sci_ arttext\&pid=S0034-72802014000100028\&lng=en\&nrm=iso.Acesso em: 10 jan. 2020.

ALMEIDA, H. G.; HIDA, R. Y.; KARA JUNIOR, N. Tendências no transplante de córnea de 2001 a 2016 no Brasil. Arq Bras Oftalmol., v. 81, n. 6, p. 529-538, 2018.

ALMEIDA, H. G; KARA JUNIOR, N. Análise crítica das diferentes fontes de dados sobre transplante de córnea no Brasil. Rev Bras Oftalmol., v. 77, n. 3, p. 142-145, 2018.

BRASIL. Ministério da Saúde. Portal Principal de Notícias da Saúde. Doação de Órgãos: transplantes, lista de espera e como ser doador. Versão: V-3.7.005, nov. 2017. Disponível em: http://saude.gov.br/saude-de-a-z/doacao-de-orgaos. Acesso em: 10 jan. 2020.

BRASIL. Ministério da Saúde. Portaria n².600, de 21 de outubro de 2009. Aprova o Regulamento Técnico do Sistema Nacional de Transplantes. Disponível em: http://bvsms. saude.gov.br/bvs/saudelegis/gm/2009/prt2600_21_10_2009.html. Acesso em: 10 jan. 2020.

BRASIL. Registro Brasileiro de Transplante. Associação Brasileira de Transplante de Órgãos. São Paulo, ano XXV, n 1, 2019.

BONFADINI, G. et al. Doação e fila de transplante de córnea no Estado do Rio de Janeiro. Rev. bras.oftalmol., Rio de Janeiro, v. 73, n. 4, p. 237-242, 2014. Disponível em: http://www. scielo.br/scielo.php?script=sci_arttext\&pid=S0034-72802014000400237\&lng=en\&nrm=iso. Acesso em: 16 jan. 2020.

BENTLEY, T.S.; PHILLIPS, S.J. U.S. Organ and tissue transplant cost estimates and discussion. United States: Milliman. 2017.

CERQUEIRA, C. S. F.; VITOR, T.C.S.; NOGUEIRA, E.C. Perfil Epidemiológico dos Pacientes na Lista de Espera para Transplante de Córnea no Estado de Sergipe. Aracaju-SE, 2016. Disponível em: https://openrit.grupotiradentes.com/xmlui/bitstream/handle/set/1551/ Carla\%20Souza\%20F.\%20de\%20Cerqueira\%20e\%20Thamires\%20Carolline\%20Santos\%20 Vitor\%20SEGUI\%20EM\%2004.\%2008.pdf?sequence=1. Acesso em dez.2019.

CRUZ, G. et al. Aspectos clínicos e epidemiológicos dos pacientes transplantados com córneas em um serviço de referência. Revista Latino-Americana de Enfermagem, Ribeirão Preto, v. 25, jun. 2017.

CRUZ, P. et al. Transplantes de córnea, perfil clínico e epidemiológico: estudo descritivo e analítico. Rev. Latino-Am. Enfermagem., Rio Grande do Norte, 2017. Disponível em: http://www.scielo.br/pdf/rlae/v25/pt_0104-1169-rlae-25-e2897.pdf. Acesso em: 13 set. 2019. 
GAIN, P. et al. Global survey of corneal transplantation and eye banking. JAMA Ophthalmol., v. 134, n. 2, p. 167-73, 2019. Disponível em: https://www.ncbi.nlm.nih.gov/ pubmed/26633035. Acesso em: 28 set. 2019.

SHARMA, N. et al. Collagen cross-linking in keratoconus in Asian eyes: visual, refractive and confocal microscopy outcomes in a prospective randomized controlled trial. Int Ophthalmol, v. 35, n. 6, p. 827-832, dez. 2015.

SMINKEY L. Priority eye diseases. 2018. Disponível em: https://www.who.int/blindness/ causes/priority/en/index8.html. Acesso em: 20 jan. 2020.

GAIN, P. et al. Global Survey of Corneal Transplantation and Eye Banking. JAMA Ophthalmol., v. 134, n. 2, p. 167-173, fev. 2016.

ZESCHAU, A. et al. Indicações de ceratoplastia: estudo retrospectivo em um Hospital Universitário. Rev. Bras.oftalmol., Rio de Janeiro, v. 72, n. 5, p. 316-320, 2013. Disponível em: http://www.scielo.br/scielo.php?script=sci_arttext\&pid=S0034-2802013000500007\&lng =en\&nrm=iso. Acesso em: 22 set. 2019. 